Post-peer review version

Schleef, Erik, Nicholas Flynn and Will Barras. Forthcoming in 2017. Regional diversity in social perceptions of (ing). Language Variation and Change.

\title{
Regional diversity in social perceptions of (ing)
}

\author{
ERIK SCHLEEF
}

University of Salzburg

NICHOLAS FLYNN

Unaffiliated Researcher

WILL BARRAS

University of Aberdeen

\section{Address of lead author:}

English and American Studies; University of Salzburg; Erzabt-Klotz-Str. 1;

Unipark Nonntal; 5020 Salzburg; Austria

Tel.: +43 (0)662 8044-4438

e-mail: erik.schleef@sbg.ac.at 


\section{Regional diversity in social perceptions of (ing)}

\section{ABSTRACT}

This article examines the perception of the (ing) variants, [In] and [In], in three regionallydistinct localities in Britain: London in the South of England; Manchester in the North; and Edinburgh in Scotland. Data was gathered in perceptual tests in which respondents from each location rated stimuli doublets, each containing only one of the variants of (ing), on multiple social attribute scales. In London and Manchester, the perception of [II]] and [In] broadly matches findings made for the US in that speakers using [In] are considered more articulate and hard-working, and less casual than speakers using [In]. In Edinburgh, results are markedly different. We argue that these differences are due to a combination of factors that include the historical development of (ing) in a particular locale, which led to differences in production, variations in language ideology and, as a result, class-specific evaluations that appear to be regionally-dependent.

\section{ACKNOWLEDGEMENTS}

This research was funded by the Leverhulme Trust (grant RPG-215, Erik Schleef PI). We are grateful to all participants in our perception surveys and those students who kindly let us use their voice samples in our experiments. We thank Maciej Baranowski, Miriam Meyerhoff and Danielle Turton for their expert advice and Ann Houston who kindly granted permission to reproduce her wonderfully illuminating map on the relation of the modern $[\mathrm{I} y] \sim[\mathrm{In}]$ alternation to the distribution of -ing in the $15^{\text {th }}$ century. Michael Ramsammy was involved in the sociolinguistic interview recordings, stimuli and survey creation for Manchester and London. Audiences at the $6^{\text {th }}$ Northern Englishes Workshop in Lancaster in April 2014 and at the $3^{\text {rd }}$ Conference of the International Society for the Linguistics of English in Zurich in 
August 2014 have provided helpful formative feedback. We alone are responsible for any failings in this paper.

\section{INTRODUCTION}

In his article, “The Child as a Linguistic Historian,” Bill Labov (1989) makes an extraordinary point: historical patterns often persist over time, and, in particular, the variation of unstressed (ing) between [Iy] and [In] as in running has a continuous history that originated respectively in the Old English verbal noun and the Old English participle. What is extraordinary is that these historical patterns continue to be produced today. While it seems that production is carried over historically, this article explores the attitudes towards (ing). One would expect production patterns and attitudes to be connected to a certain extent and, possibly, differ regionally as historical patterns have resulted in different sociolinguistic profiles of production in different locales.

However, learning and using variation in (ing) and developing attitudes towards (ing) are rather different processes, although they are surely connected. In particular, what is unclear is how these (historically-motivated) production patterns relate to synchronous attitudinal patterns: are attitudes the same in different locales and only differ in effect size, are attitudes qualitatively different, are attitudes socially stratified? This is important because answers to these questions tell us how attitudes to a specific variable may vary regionally, in addition to what degree of attitudinal variability we may encounter within a speech community. This is a useful question because evaluative norms are used frequently to define speech communities (e.g., Labov, 1972:117); however, recent perception-based research demonstrates that some speakers, even within the same speech community, may hold attitudes that are different from those of other speakers (Levon \& Fox, 2014; Preston, 2010). 
One way to investigate these issues is to explore regional variation in the use of (ing) in Britain, where historical developments have led to different outcomes in some parts of Britain compared with others. These continue to be reflected in varying frequencies in the use of [II], particularly when comparing southern and central varieties in England with those of the far north and the periphery of England, as well as Scotland (Houston, 1985). We examine the perception of the (ing) variants in three regionally-distinct localities in Britain: London in the South of England; Manchester in the North of England; and Edinburgh in Scotland. We are interested in socio-indexical meanings and how, why and, indeed, if they differ crossdialectally, as well as between speaker groups within a locale.

We begin by providing some background information on the use of (ing) in Britain, before exploring its social meanings in Britain and beyond. An analysis is then presented of the perception of the (ing) variable in London, Manchester and Edinburgh. Our results reveal strong evidence of regionally different attitudes towards (ing). We argue that these differences are due to a combination of factors that include the historical development of (ing) in a particular locale, variations in language ideology and, consequently, class-specific evaluations that appear regionally-dependent.

\section{GEOGRAPHICAL VARIATION IN (ING)}

\section{Historical development and current situation}

One argument that has been proposed as an explanation of why levels of [II] may differ regionally within Britain relates to the historical development and regional spread of the -ing suffix. It will be instructive to review this briefly and locate London, Manchester and Edinburgh within this history of (ing). Variation in (ing) developed from the coalescence of at least two grammatical forms during the Middle English period: the present participle and a verbal noun. Visser (1966:1081) tells us that in later Old English, the form -inde - the 
precursor to [In] - prevailed in the present participle forms in southern districts, while in midland districts it was -ende. The final syllabic/ə/ eventually became mutescent, as elsewhere in similar environments, resulting in -ind and -end. Moreover, there was a tendency for the /d/ to be dropped in particular positions and under certain conditions, and these forms eventually became -in and -en. Northern districts had the form -ande and developments were similar but occurred later.

In late Old English, the verbal noun ending in -ung, - unk, -ynge or -ing - the precursor to [II] - tended to be pronounced without the final consonant (Visser, 1966:1083). This process resulted in the pronunciation of $<\mathrm{ing}>$ as /in/, which was often replaced by /In/ in the Middle English period, so that the present participle and the verbal noun shared the same ending. It is possible that Phonological Coalescence resulted in hypercorrection (Visser, 1966:1086) or mere confusion as scribes now often added $<$ g $>$ to the participle form too. ${ }^{1}$

The substitution of -ind with -ing began in southern districts due to its similarity in the reduced form there already (Visser, 1966:1096). This led to an expansion of the -ing ending, which displaced previously-used endings. In central and northern districts -end and -and prevailed, and it took a considerable amount of time for the ending -ing to spread into these areas. This extended diffusion process of -ing resulted in a large degree of variation in how the suffix was spelled in the Middle English period (Visser, 1966:1096). The [In] [In] variation has, thus, been present in southern dialects longer than in other dialects of Britain, which may explain why [In] remains present in higher quantities in the periphery and the North. Houston (1985:108) suggests there are two dialect groups in this regard: the southern or internal group where [II] is used frequently; and the northern and peripheral group where it is used less. 


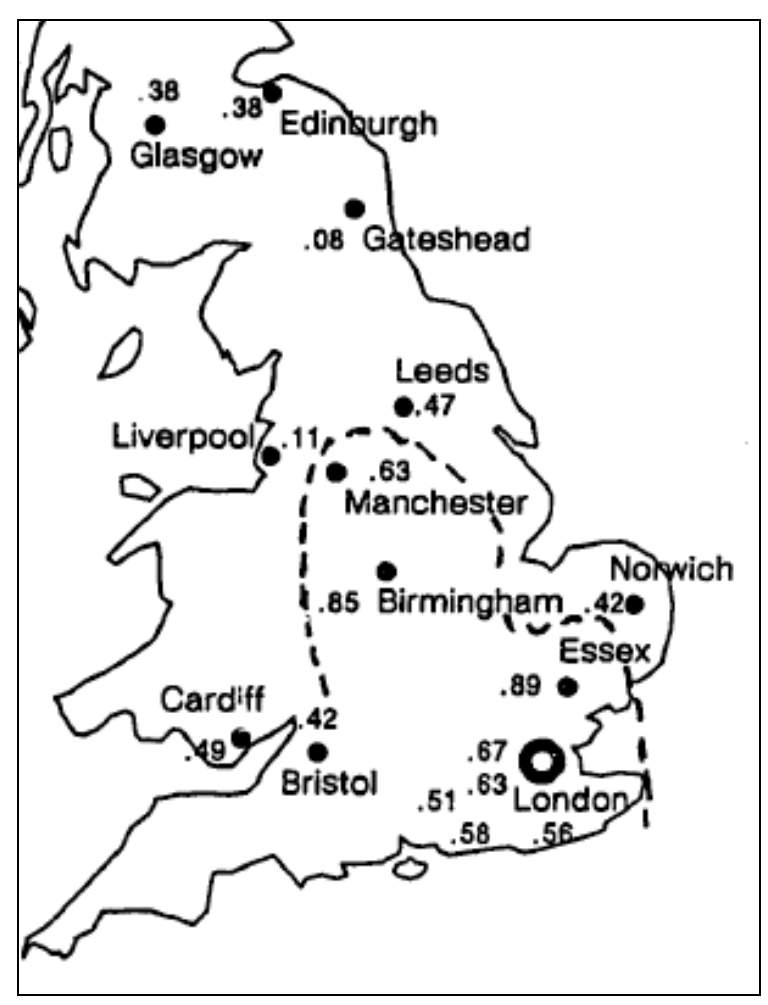

FIGURE 1: Modern [II] [In] alternation as probabilities for velar (ing) in relation to the Northern limits of the -ing present participle in the 15th century (Houston, $1985: 105)$

Figure 1 from Houston (1985:105) illustrates the relation of the modern [II] [In] alternation to the distribution of -ing in the 15 th century. Numbers indicate the probability of the [II] variant, based on a VARBRUL analysis of 60 speakers interviewed in the 1970s in 16 communities. The dashed line separates those southern and internal areas where [Iy] appears with values above .50 (including London and Manchester) from those northern and peripheral areas where it is below .50 (including Edinburgh). As both Houston and Labov (1989) have pointed out, this line of the modern distribution of (ing) matches one established by Moore, Meach and Whitehall (1935), which indicates the 15th century northern limit of the -ing present participle as it spread into Northern and peripheral areas. Thus, [In] remains present in higher quantities in the latter areas (as shown in Houston's [1985] figures) because the 
diffusion of -ing reached them at a later point in time as compared to the non-peripheral areas. It is often forgotten in publications following Houston that the main division is not one of north versus south; rather, it is one of internal versus peripheral.

Both London and Manchester are located in what Houston refers to as the internal/southern area where the modern [Iy] $\sim$ In] alternation has been in existence for quite some time, while this is not the case for Edinburgh. Houston (1985:103), focusing on working-class (WC) speech, cites [II] values of 20 to 42\% (London), 21\% (Manchester) and $18 \%$ (Edinburgh) respectively for these locations. Other studies confirm this trend. London clearly shows the highest use of [In] with, for example, $65 \%$ of [Iy] use among lower middleclass (MC)/upper WC adolescents in interview speech, but 8\% [II] use among lower MC/upper WC adolescents in Edinburgh interview speech (Schleef et al., 2011:235), while Romaine (1984:98) reports zero \% in Edinburgh WC but 12\% in MC peer group interaction ( $10 \%$ and $26 \%$ in interview speech respectively).

From the existing body of research on (ing), a small number of internal and external factors have been identified as consistently constraining its variation (see Hazen [2006] for a brief overview). Socioeconomic class is one such factor with [In] used more frequently by speakers of a lower socioeconomic class. It seems that social class interacts with regional area and the baseline frequency of [In] in a particular area (e.g., Labov, 2001:90). A number of studies exemplify this point for locations in Britain such as London (Schleef et al., 2011), Sandwell, West Midlands (Mathisen, 1999), Wilmslow, Cheshire (Watts, 2005), Manchester (Schleef, Flynn, \& Ramsammy, 2015), Cardiff (Mees, 1977), Norwich (Trudgill, 1974), York (Tagliamonte, 2004), and Edinburgh (Romaine, 1984; Schleef et al., 2011). Data from some of these studies suggest that the lower middle classes in northern cities stand out as relatively low users of [Iy], with numbers often as low as for working class speakers in southern cities. This is an important point to which we return in our discussion. 
Patterns based on speaker sex and speech style have also been noted, with [In] used more frequently by males (Hazen, 2006). The presence of [In] decreases in more formal speech styles (Hazen, 2006; Labov, 2001; Reid, 1978; Romaine, 1984; Schleef et al., 2011; Trudgill, 1974). In varieties where [Ing] occurs as a third variant of (ing), as is the case for Manchester English, [Ing] too is more plentiful in formal styles (Mathisen, 1999; Schleef et al., 2015; Watts, 2005). We exclude [Ing] from the current analysis (Schleef \& Flynn, 2015). ${ }^{2}$

The social and stylistic stratification of (ing) is similar in the US and Britain, with some differences reported in the variable's sociolinguistic conditioning and social meaning. Tagliamonte found little symbolic social value attached to (ing) in York, a northern British city. Social class is the only social factor that achieves statistical significance and its effect size is not particularly strong. This is very different from the much more extreme sociolinguistic conditioning reported for the US, Australia and, notably, southern England (Tagliamonte, 2004:401). The respective sociolinguistic conditioning may at least partially have influenced how (ing) is evaluated socially in Britain and elsewhere.

\section{Social evaluation}

Detailed research is available about the social perception of (ing); in particular on the social evaluation of (ing) in the US: [In] is normally evaluated more negatively than [Iy], as demonstrated by Labov, Ash, Ravindranath, Weldon, Baranowski, \& Nagy (2011). In their experiments, respondents were asked to rate speakers' suitability for a newsreader position using the scale of professionalism. There was a clear and statistically significant trend for speakers with higher proportions of [In] in their speech to be rated as less professionalsounding. However, Levon \& Fox (2014) replicated Labov et al.'s (2011) study with undergraduate students at the University of London, and discovered that the same patterns 
were not present. Levon \& Fox (2014) argue that this is due to (ing) having less social salience in Britain than in the US.

They suggest that the relation between class and (ing) is "less straightforward in Britain than it is in the United States" (Levon \& Fox, 2014:201) as many MC speakers in the North use the alveolar and many WC in the South use the velar form (Levon \& Fox, 2014:199-200). Certainly the results of their newsreader experiment suggest that speakers in Britain are aware of variation in (ing), but it does not seem to hold the same degree of social prominence as in the US. Reasons for this differential variation are varied. In Britain, use of [In] is associated not only with the WC, but also the gentry. Jesperson (1961:356) observes that "the aristocracy, and 'horsy' people generally, are said to favour [In]," which we continue to come across in stylisations of social types relating to these concepts. Thus, based on these findings, it is likely that results for the US and (different areas within) Britain may differ-certainly on the professionalism scale, but (ing) is associated with a variety of different attributes.

Campbell-Kibler $(2007,2009,2011)$ in research on the perceived social meanings of the variants of (ing) in the US found that [In]-guises were rated as significantly more educated, intelligent, articulate-sounding and less likely to be a student, while [In]-guises were rated as sounding significantly more informal and less likely to be gay-sounding. In her (2009) study, Campbell-Kibler also found [II] guises to be rated as hardworking and associated with the American West Coast, while [In] guises were considered bored yet polite. This line of research has also demonstrated the context-dependency of social meanings. Indexicalities of variants are vague, complex, contestable and underspecified. Thus, comparisons to other studies are somewhat limited, as we can only compare those social meanings that emerge above variation in topic, although other contexts may generate additional meanings. Eckert (2008:466) illustrates how the interrelated potential social attributes linked to the variants of 
(ing) can be organised into an indexical field, "a constellation of meanings that are ideologically linked” (2008:464).

We are interested in these meaning constellations, but we also wish to explore an additional layer of meaning in this study: one based on respondent background. We explain here why this matters. Social meanings of variants are under-specified (Eckert, 2012:22). Based on abstract meanings, relevant social meanings emerge in specific social settings, and these meanings may depend on a variety of factors; for example, listeners' expectations, experiences, beliefs, attitudes and various contextual conditions, such as the information available to the listener about the speaker (e.g. Campbell-Kibler, 2007; Hay, Drager, \& Warren, 2010; Pharao, Maegaard, Møller, \& Kristiansen, 2014).

If we take these deliberations on listeners' expectations, experiences, etc., and combine them with our review of the potential regional and class variations in social meanings of (ing), we arrive at an obvious conclusion: the same variable is used by people from very different backgrounds at varying frequencies across Britain; consequently, it is likely that social meanings may differ across populations - regionally and socially. Not only the linguistic form would then appear to be subject to social variation, but the meaning of the form as well. Johnstone and Kiesling (2008) make this point very clearly, while Eckert (2008:467) makes a very specific suggestion concerning (ing), social class, formality and displays of education: "If I am correct in my assumption that class differences involve ideological differences about formality and displays of education, then one might expect working-class speakers to have the more positive evaluations of this form and middle-class speakers to have the more negative ones." Thus, apart from exploring the social meanings that can be ascribed to (ing) variants in British English varieties, we will also be able to compare different speaker groups, as our data is quite varied in this respect. Uncovering how attitudes and production sync with each other 
is an important step in explaining how production differences have been maintained throughout the centuries.

In conclusion, we will attempt to answer the following questions: (1) What social meanings do listeners associate with the variants of (ing) in Britain: do they differ in varieties of English? (2) If so, how do (historically-motivated) production patterns relate to synchronous attitudinal patterns? (3) Do listeners from different social backgrounds evaluate (ing) differently? In order to answer these questions, we have conducted an experimental study, which involved participants listening to doublets of conversational speech excerpts that differed only in the (ing) variant. Thus, if the variant turns out to be a significant main factor, significant differences cannot be due to the content of the stimulus nor any aspects of the voice heard. We will now describe the methodological steps taken in our study.

\section{DATA AND METHODS}

\section{Creating Stimuli}

In creating perceptual stimuli, first, semi-structured, one-to-one sociolinguistic interviews lasting around one hour each were recorded. The interviews comprised casual conversation on a narrow range of topics. Males and females aged 18-20 from all three locations were recorded wearing high-quality, head-mounted microphones (Beyerdynamic Opus 55 MkII), using a Zoom H4 recorder at a sampling rate of $44.1 \mathrm{kHz}$.

Extracts from each interview, containing several instances of the linguistic variable under investigation, were identified as possible contenders for stimuli in perceptual experiments. These extracts were used in pilot studies, held separately in each locale, to choose the local speakers and extracts most suitable for use in the final perceptual experiments. Respondents were given a paper survey, which asked them to rate each voice in terms of attractiveness, perceived age, occupation, etc. on a scale of 1 (a low score) to 6 (a high score). Based on this 
pilot study, we were able to identify speakers whose voices were perceived overly negative or positive, or who did not sound as though they came from the regions in which we were interested: the cities of Edinburgh, Manchester and London. Based on the results of the pilot study, we selected speakers from each location who had all received similarly moderate scores for attractiveness, social class and age. Thus, we selected only voices who were judged as those of 18-24 year-old speakers and whose attractiveness and social class mean rating was between 2.1 and 3.9.

To create the perceptual stimuli for use in our surveys, we adopted a method similar to Campbell-Kibler (2007). The speakers chosen participated in a second recording session. Extracts from their own interview containing several instances of (ing) were presented to them orthographically on a computer screen, in addition to being played to them. Speakers listened to the extract and then twice re-enacted what they had originally said; thereby matching the tempo and intonation of the original recording, firstly with (ing) realised solely as [II] in every occurrence, and secondly with (ing) realised solely as [In] in every instance. An example extract for (ing) is given below:

I like the big wheel. I didn't actually go on it this year, never got around to it. It's actually sad when that goes. Although. The wheel com(ing) down does mean January sales. But. I'm actually sav(ing) up my money, so I'm not go(ing) into town to shop at all.

Perceptual stimuli were then created in Praat (Boersma \& Weenink, 2014) by taking each original extract and cross-splicing the (ing)-realisations from the second recording sessions into the original recording in place of the original deleted (ing)-productions. This resulted in 2 
stimuli for each speaker; completely identical except for the realisation of (ing), which was always [In] for one stimulus, and [In] for the other.

Next, stimuli were played to focus groups comprising undergraduate students, again separated by locale, using only the respective stimuli of the respective local speakers. Focus groups took the form of a recorded group interview in which participants were asked to discuss what the speakers sounded like. This provided us with the vocabulary items that nonspecialists are likely to use and understand when discussing speakers and their social attributes.

\section{Perceptual Experiments}

The perceptual experiments were conducted through online surveys. The (ing) stimuli were part of a larger study that also tested other variables. Three sets of surveys were prepared, one for each locale. Each local survey set consisted of several sub-surveys, which included different stimuli. Depending on locale, five, six or seven online sub-surveys were generated using FluidSurveys, an online survey software, with the goal of eliciting information on the evaluation of the (ing) stimuli pairs but also stimuli pairs for the variables ( $t$ ) and (th), which are not part of this paper. In each of these stimuli pairs, only one variable was manipulated. Apart from this one variable, everything else in each pair was identical.

Four stimulus voices were presented in each sub-survey. For example, in London, a total of six sub-surveys were used, each of which included four stimuli from different speakers and excerpts of these that focused on a different variant of (ing), (t) or (th). Thus, no participant heard the same extract twice, reducing carry-over effects, and they would come across at least one (t) guise, one (th) guise and one (ing) guise in each survey. This made it impossible for listeners to identify the target segment, as every listener heard only one of the stimuli pairs per extract. ${ }^{3}$ 
Here, we analyse the responses for three (ing) doublets (each doublet from a different speaker) in each locale; that is, each of three speakers ${ }^{4}$ per locale was heard using [II]]. In another sub-survey, the same excerpt was played with only [In]-realisations. Thus, we are analysing here a total of six stimuli per locale (see appendix).

To participate in the surveys, respondents were required to have lived in the London, Greater Manchester or Edinburgh area for at least 15 years. ${ }^{5}$ Respondents were reimbursed for their efforts with a $£ 5$ gift certificate. We limited guises to listener region: Londoners heard London stimuli, Mancunians heard Manchester stimuli, and Edinburghers heard Edinburgh stimuli. Thus, we are not testing how evaluations may be different if respondents hear (ing) in a variety that is not their own. We assume that this would make a difference. Walker, García, Cortés, \& Campbell-Kibler (2014) demonstrate that respondents do not simply apply their own symbolic usage of a variable feature, but take into account the dialect of the speaker. While it would have been interesting to see how (ing) is evaluated in a variety that is different from a listener's, such a move would have trebled the number of surveys we would have had to conduct in each locale, which was beyond our resources.

Survey respondents in London, Manchester and Edinburgh areas listened to a stimulus and were then asked to provide judgements about the voice speaking. Firstly, the voice was rated on multiple pre-defined seven-point scales, each one corresponding to a different social attribute, with opposite character traits defining the endpoints of the scales. The survey was set-up to present the social attributes in a random order, so as to avoid order effects. The social attributes that were tested in all three locales are listed in Table 1. They are based on comments received during the focus-group stage and previous research; notably, the important study conducted by Zahn \& Hopper (1985).

TABLE 1. Scales included in all perceptual surveys 


\begin{tabular}{ll}
\hline articulate $\sim$ inarticulate & down-to-earth $\sim$ pretentious \\
correct $\sim$ incorrect & friendly $\sim$ unfriendly \\
educated $\sim$ uneducated & sincere $\sim$ fake/two-faced \\
intelligent $\sim$ thick & \\
posh $\sim$ common & \\
very rich $\sim$ not at all rich & \\
very working-class $\sim$ not at all working-class & \\
\hline casual formal & masculine $\sim$ feminine \\
confident $\sim$ self-conscious & tough $\sim$ soft \\
hard-working $\sim$ lazy & trendy/hip $\sim$ untrendy \\
outgoing/sociable $\sim$ shy & very urban $\sim$ not at all urban \\
laidback $\sim$ uptight & perceived age: $14-18,18-25,26-35$, \\
& $36-50,50+$ \\
&
\end{tabular}

Furthermore, respondents were asked to indicate whether they considered the stimulus voice as matching that of a student or teacher. Finally, self-reported demographic information about the respondent was collected: age (continuous), sex (male, female), self-assessed social class (WC, MC, other), hometown, native language (English, other). Surveys were designed to be completed in approximately 5 to 10 minutes.

\section{Data Analysis}

Responses to (ing) stimuli were extracted from the total survey responses. Responses with a completion time of less than 5 minutes were removed, as it was judged that it would take longer than this to answer a survey in full and provide meaningful answers. Respondents whose native language was not English, and who were not born, brought up, or currently 
reside in the target area were also discarded. Responses from non-UK IP addresses were deleted, as were incomplete surveys, and respondents whom we deemed untrustworthy (e.g., based on contradictory personal data). Responses consisting of a continuous rating (e.g., 3) for every answer were also removed. ${ }^{6}$ The number of listeners with continuous evaluations were small and never exceeded five per locale. Since the age range of respondents was wider in London and Manchester than in Edinburgh, we also excluded all respondents older than 29; thereby ensuring the results for Edinburgh are comparable with those of the other two cities. This left the following number of $[\mathrm{I}]] \sim[\mathrm{In}]$ responses:

- 332 for the London survey (139 female, 193 male, 173 MC, 159 WC),

- 266 for the Manchester survey (180 female, 86 male, 99 MC, 167 WC), and

- 237 for the Edinburgh survey (110 female, 127 male, $154 \mathrm{MC}, 83 \mathrm{WC})$.

Respondent ratings were subjected to statistical testing using R (R Core Team, 2014). ${ }^{7}$ Mixed effects linear regression (lmer) was used for the social attributes, while mixed effects logistic regression (glmer) was used for the personae of student and teacher. As random effects, we had intercepts for respondent, in addition to by-respondent random slopes for the effect of variant. The ratings for social attributes were treated as the response variable with the following five contrast-coded, fixed-effect predictors:

- Variant present in the stimulus: [In], [II]].

- Respondent sex: male, female.

- Respondent social class: working-class (WC), middle-class (MC).

- Respondent Age: continuous (15-29 years).

- Speaker: speaker 1, speaker 2, speaker 3 in each locale

We chose to include speaker as a fixed, rather than a random effect, in order to conduct a maximally transparent check on whether any patterns detected hold across all speakers. We 
also checked for interactions between variant and all other predictors. ${ }^{8}$ We turn now to present our results.

\section{RESULTS}

Since every scale results in a unique regression model in London, Manchester and Edinburgh, we are unable to provide full models for all scales. Instead, we present in Tables 3 to 5 an overview of results summarising those models in which variant was a significant factor. We also present one full model in Table 2 to explain how we arrived at the numbers given in Tables 3 to 5. Table 2 reveals how respondents in London rated the two guises of the three London speakers for their perceived level of education. The model indicates that the guise is significant; in other words, whether respondents heard [II] or [In] matters. The [In]-guises are heard as less educated than the [In]-guises. The estimates given for main effects in the regression model help us interpret the effect that presence of one variant rather than another has on the rating given by respondents. Crudely, a positive value indicates that a higher rating than the reference predictor ([In]) is associated with the factor, while a negative value indicates that a lower rating than the reference predictor is associated with the factor. Here, [In] is associated with a lower value: it is rated as less educated. Other social factors, such as respondent gender, age or social class, were not significant, neither as a main effect, nor in interaction with variant. Thus, the evaluation for educatedness holds across all social groups investigated.

There is a significant main effect for speaker. Logan's stimuli are rated as more educatedsounding than those of the speaker entered as the reference level (Lara). Thus, regardless of whether respondents heard Logan's [II] or [In] guise, these guises were always rated higher on education than Lara's. This is not surprising. Voice and topic can certainly influence how a speaker is evaluated, and it does not undermine the goal of this investigation in any way; 
namely, to discover whether the presence of [Iy] or [In] influences the evaluation of a voice. Since the two Logan guises differed only in the presence or absence of [II] or [In], differing evaluations of speakers do not really constrain our research goals.

It is, of course, possible for the evaluation of a voice to influence how [II] or [In] are evaluated, i.e., voice and variant may interact. Such effects have been documented (e.g., Campbell-Kibler, 2009), and we would expect to see interactions between speaker and variant in our model if such an effect occurred. This is not the case in Table 2; in fact this does not happen at all in the London data. It occurs for one scale in Manchester and for one in Edinburgh. We also provide mean values for every speaker in the appendix to document that all three speakers tend to be evaluated similarly, which may be due in part to our rigorous voice selection process. In the absence of such interaction effects between speaker and variant, it is appropriate to state that the results for the evaluation of [In] and [In] hold across all three London speakers.

TABLE 2. Summary of best mixed-effects model for educated $(N=332)$ in London with [II] and Lara as reference levels

\begin{tabular}{lcccc}
\hline \hline & Estimate & Std. Error & $t$-value & $p$-value \\
\hline Intercept & 0.93 & 0.16 & 5.97 & $<0.01$ \\
Variant [In] & -0.37 & 0.14 & -2.63 & 0.01 \\
Speaker (Lola) & -0.21 & 0.17 & -1.19 & 0.24 \\
Speaker (Logan) & 0.37 & 0.18 & 2.07 & 0.04 \\
\hline \hline
\end{tabular}

Tables 3-5 list the results for all 12 scales for which variant was significant in at least one of the three locations. Variant was not significant for 10 scales, and they will not be discussed 
any further: confident, correct, laidback, masculine, outgoing, perceived age, sincere, student, tough and urban. We will discuss the results in three stages:

(1) Shared social meanings in London and Manchester. Here we discuss articulate, hardworking, posh, rich and the London-specific social meaning of working-class.

(2) Social meanings that may be shared among certain groups in the London, Manchester and Edinburgh population, where Manchester often holds an intermediate position. Here, we discuss educated, teacher, intelligent and casual.

(3) Edinburgh-specific scales: down-to-earth, friendly and trendy.

Tables 3-5 list relevant scales (column 1) and places (columns 2-4), the estimate of the intercept for every model (I), the estimate (E) for [In] and the $p$-value (P). The em-rule (-) indicates no significant main or interaction effect for the variant heard. The symbols $>$ and $=$ indicate effect direction, for example Variant: [II] > [In] under articulate means that [II]guises are heard as more articulate than [In]-guises, while = indicates no difference in evaluation. Two factors separated by an asterisk indicate a significant interaction effect. For example, variant ${ }^{*}$ sex would indicate the male respondents and female respondents differed significantly in their ratings of one of the stimuli in relation to another.

Shared social meanings in London and Manchester

TABLE 3. Significant effects for evaluation scales in London and Manchester (Reference level is [II])

\begin{tabular}{|l|l|l|l|}
\hline Significant & London & Manchester & Edinburgh \\
scales & & & \\
\hline
\end{tabular}




\begin{tabular}{|c|c|c|c|}
\hline Articulate & $\begin{array}{l}\text { Variant: [In] > [In] } \\
\text { I: 0.93, E: -0.31, P: } 0.04\end{array}$ & $\begin{array}{l}\text { Variant: }[\mathrm{I \eta}]>[\mathrm{In}] \\
\text { I: } 0.51, \mathrm{E}:-0.28, \mathrm{P}:<0.05\end{array}$ & - \\
\hline $\begin{array}{l}\text { Hard- } \\
\text { working }\end{array}$ & $\begin{array}{l}\text { Variant: [In] > [In] } \\
\text { I: } 0.69, \text { E: }-0.31, \text { P: } 0.02\end{array}$ & $\begin{array}{l}\text { Variant: [II] }>\text { [In] } \\
\text { I: } 0.62, \text { E: }-0.46, \text { P: }<0.01\end{array}$ & - \\
\hline Posh & $\begin{array}{l}\text { Variant: [In] }>[\mathrm{In}] \\
\text { I: } 0.19, \text { E: }-0.40, \mathrm{P}:<0.01\end{array}$ & $\begin{array}{l}\text { Variant: [In] > [In] } \\
\text { I: }-0.12, \text { E: }-0.68, \text { P: }<0.01 \\
\text { Variant*social class } \\
\text { MC: }[\mathrm{I} \mathrm{I}]>[\mathrm{In}] \\
\text { WC: }[\mathrm{In}]=[\mathrm{I}]] \\
\text { I: }-0.12, \text { E: } 0.73, \text { P: } 0.01\end{array}$ & - \\
\hline Rich & $\begin{array}{l}\text { Variant: }[\mathrm{In}]>\text { [In] } \\
\text { I: } 0.37, \text { E: }-0.36, \text { P: } 0.02\end{array}$ & $\begin{array}{l}\text { Variant: [II] > [In] } \\
\text { I: -0.14, E: -0.68, P: } 0.01 \\
\text { Variant*speaker } \\
\text { Morgan, Max: [In] > [In] } \\
\text { Mandy: [In] > [In] } \\
\text { I: -0.14, E: 1.19, P: <0.01 }\end{array}$ & - \\
\hline $\begin{array}{l}\text { Working } \\
\text { class }\end{array}$ & $\begin{array}{l}\text { Variant: [In] > [In] } \\
\text { I: }-1.78, \text { E: } 0.74, \text { P: }<0.01 \\
\text { Variant*sex } \\
\text { Male: }[\mathrm{I} \mathrm{I}]=[\mathrm{In}] \\
\text { Female: }[\mathrm{In}]>[\mathrm{I}]] \\
\text { I: } 1.78, \text { E: }-0.93, \text { P: }<0.01\end{array}$ & - & - \\
\hline
\end{tabular}


Table 3 indicates that the variant present in the stimulus was found to be statistically significant in conditioning the respondent ratings for four scales in both London and Manchester without showing significant evidence that (ing) mattered for these scales in Edinburgh. ${ }^{9}$ Speakers using [Iy] were evaluated as significantly more articulate, more hardworking, posher and richer-sounding than the same speakers using [In] — see also Figures 2 to 5, which give means and standard errors (SE). In London, these are all main effects, which is an indication that these effects hold across age, gender and class strata. In London, the [In]-stimulus is also heard as more WC. This is the only London-specific effect, and it does not hold across all participant groups. It is an effect that is due largely to female respondents. Nonetheless, it is fair to say that, based on our findings for articulate, hardworking, posh, rich and working class, in London, [In] is associated very strongly with characteristics such as articulate speech, diligence and a certain amount of wealth and refined demeanour.

To an extent, this is also the case in Manchester. There are main effects without any interactions for articulate and hardworking. For posh and rich, too, the expected main effects occur; however, here interaction effects indicate that evaluations may not hold across the board. Only MC respondents considered the [II]-guises posher than the [In]-guises, and only two of the three voices are heard as richer in the [Iy]-guise than in the [In]-guise. Thus, while [II] is associated very strongly with articulateness and diligence, [In]-guises do not evoke the same connotations of wealth and refined demeanour across the entire population in Manchester. 


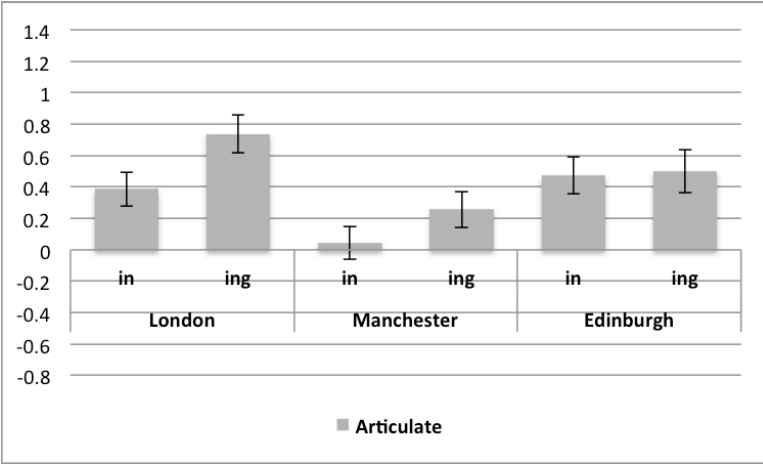

FIGURE 2. Means for articulate.

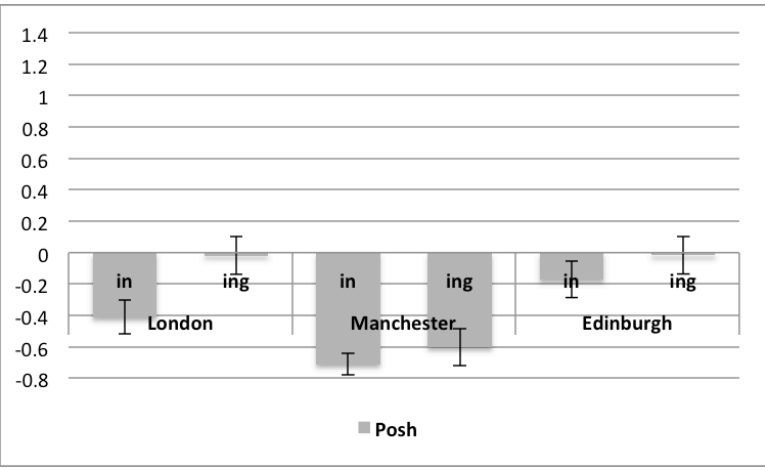

FiguRE 4. Means for posh.

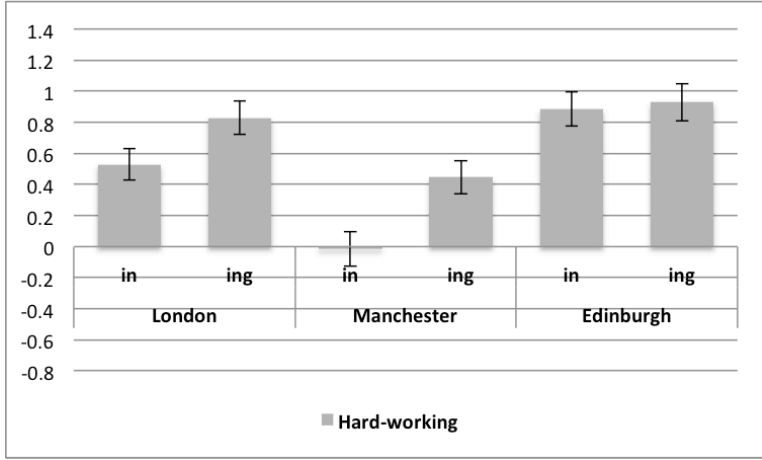

FIGURE 3. Means for hard-working.

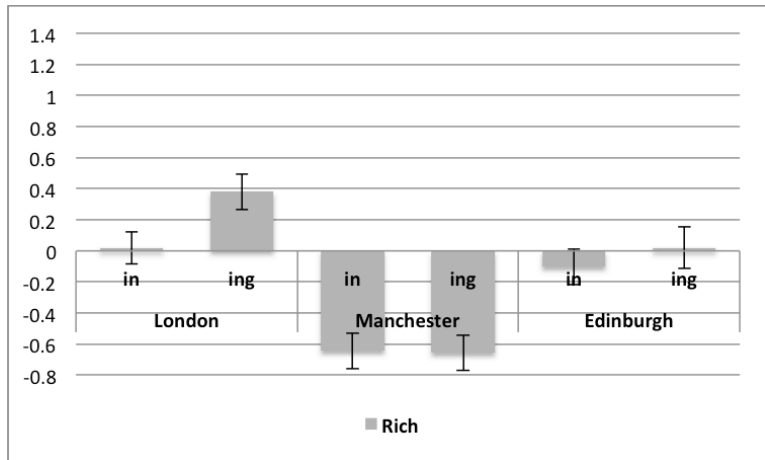

FIGURE 5. Means for rich.

Shared social meanings in London, Manchester and Edinburgh

When we move on to the scales of educated, teacher, intelligent and casual, the results become rather more complex (see Table 4). We would like to make three main points in this section. First, it is noteworthy that all of these scales relate to education and formality in one way or another. Second, regression models indicate an evaluative shift as we move from London to Manchester and Edinburgh. Finally, we observe a high degree of evaluative heterogeneity in Edinburgh among subgroups of the population. 
TABLE 4. Significant effects for evaluation scales related to education and formality (Reference level is [II])

\begin{tabular}{|c|c|c|c|}
\hline $\begin{array}{l}\text { Significant } \\
\text { scales }\end{array}$ & London & Manchester & Edinburgh \\
\hline Casual & $\begin{array}{l}\text { Variant: [In] }>\text { [In] } \\
\text { I: } 0.68, E: 0.50, P<0.01\end{array}$ & 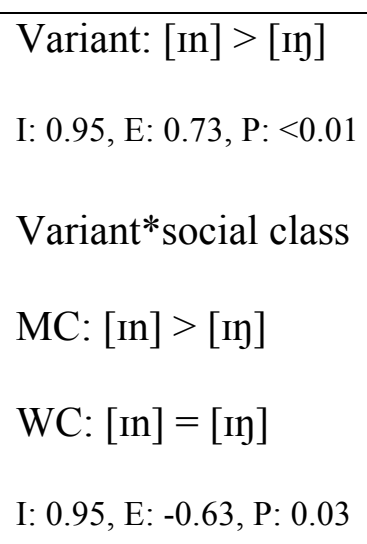 & $\begin{array}{l}\text { Variant*social class } \\
\text { MC: }[\mathrm{In}]>[\mathrm{I}] \\
\text { WC: }[\mathrm{I}]]>[\mathrm{In}] \\
\text { I: } 1.04, \text { E: }-0.76, \text { P: } 0.04\end{array}$ \\
\hline Educated & $\begin{array}{l}\text { Variant: }[\mathrm{In}]>[\mathrm{In}] \\
\text { I: } 0.93, \mathrm{E}:-0.37, \mathrm{P}:<0.01\end{array}$ & - & $\begin{array}{l}\text { Variant*social class } \\
\text { MC: }[\mathrm{II}]>[\mathrm{In}] \\
\text { WC: [In] }>\text { [In] } \\
\text { I: } 2.53, \text { E: } 0.63, \text { P: }<0.05\end{array}$ \\
\hline Teacher & $\begin{array}{l}\text { Variant: [II] > [In] } \\
\text { I: -1.25, E: -4.6, P: } 0.03 \\
\text { Variant*age } \\
\text { Younger: [In] > [In] } \\
\text { Older: [In] > [In] } \\
\text { I: -1.25, E: } 0.22, \text { P: } 0.04\end{array}$ & - & $\begin{array}{l}\text { Variant: [In] > [In] } \\
\text { I: -2.73, E: 23.53, P: } 0.03 \\
\text { Variant*age } \\
\text { Younger: [In] = [In] } \\
\text { Older: [In] > [In] } \\
\text { I: -2.73, E: }-1.52, \text { P: } 0.03\end{array}$ \\
\hline Intelligent & - & - & - \\
\hline
\end{tabular}




\begin{tabular}{|l|l|l|} 
& Variant*sex & Variant*sex \\
Male: $[\mathrm{In}]>[\mathrm{In}]$ & Male: $[\mathrm{In}]>[\mathrm{In}]$ \\
Female: $[\mathrm{In}]>[\mathrm{In}]$ & Female: $[\mathrm{In}]>$ [In] \\
& I: 0.04, E: -0.66, P: 0.03 & I: 0.36, E: -0.71, P: $<0.05$ \\
\hline \hline
\end{tabular}

We start elaborating on these last two points by inspecting the results for the casualformal scale. In contrast to the previous five scales, the formality scale matters in all three locales but clearly differs regionally (see Figure 6). While there is a main effect in the two English cities ([m] is heard as more casual), in Manchester the results are also constrained by class membership. This is also the case for Edinburgh, where only an interaction effect emerges. Thus, as we move north, the evaluation of (ing) on the casual/formal scale becomes increasingly heterogeneous. While in Manchester MC respondents still seem to agree that [In]-stimuli sound more casual than [Iy]-stimuli, working class respondents in Manchester do not perceive a difference. Similarly, in Edinburgh MC respondents hear [In]-stimuli as sounding more casual than [In]-stimuli. WC respondents, however, rate [In]-stimuli as more formal sounding than [Iy]-stimuli, whilst values for the latter differ little between the two classes.

A similar pattern can be observed for educated (see Figure 7). In London [Iy]-stimuli are rated as more educated across the entire population, in Edinburgh only MC respondents hold this view, while in Manchester no significant results emerge at all. Thus, it seems that heterogeneity of evaluation in Edinburgh arises out of social classes evaluating variants of (ing) differently.

Such evaluative heterogeneity can also be based on participant sex and age. We observe such effects for the intelligent scale in Edinburgh and Manchester. Males tend to regard [In]- 
stimuli as more intelligent-sounding, while females hold the opposite view. This scale does not rise above significance in London at all. To those who associate [In] with intelligence, speakers who use [In] may seem odd and less intelligent, because [II] use is not a behaviour that would normally be expected in local casual conversation. It is reminiscent of CampbellKibler's (2009) finding that for one of her speakers the [Iy]-stimulus made the speaker sound less intelligent. Based on interview data, Campbell-Kibler inferred that listeners thought the speaker used [II] in order to sound more intelligent than she was. While in her study this was limited to one speaker, in Edinburgh and Manchester this may hold across certain social groups. Many females in Edinburgh and Manchester may think that the [Iy]-variant does not quite belong into young people's conversational speech. Considering [In] is indeed the more likely variant in this activity type, it is females who demonstrate an impressive degree of introspection.

Finally, we observe a very telling example for Teacher, which highlights the very different status of the variable (ing) in London and Edinburgh. In London, [II] is associated with teachers, especially among younger respondents. In Edinburgh, [In] and [II] are associated equally with teachers among younger respondents. This may be due to younger respondents being in actual daily contact with teachers and their responses may be more in line with what is happening in the classroom; meanwhile, the evaluations of older respondents, who associate teachers with [Iy], may, to a larger degree, be influenced by public discourses, ideologies and stereotypes. Thus, the association of (ing) with the educational domain appears to be a fundamentally different one in London and Edinburgh, while in Manchester its connections with this domain are less transparent and less in line with how Londoners evaluate (ing). 


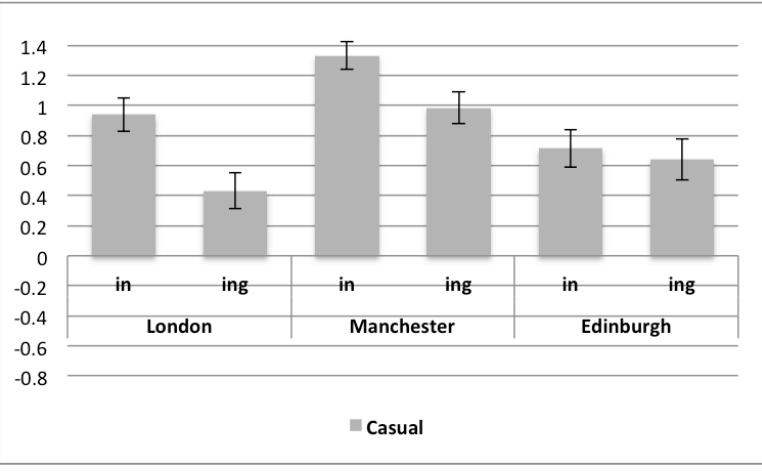

FIGURE 6. Means for casual.

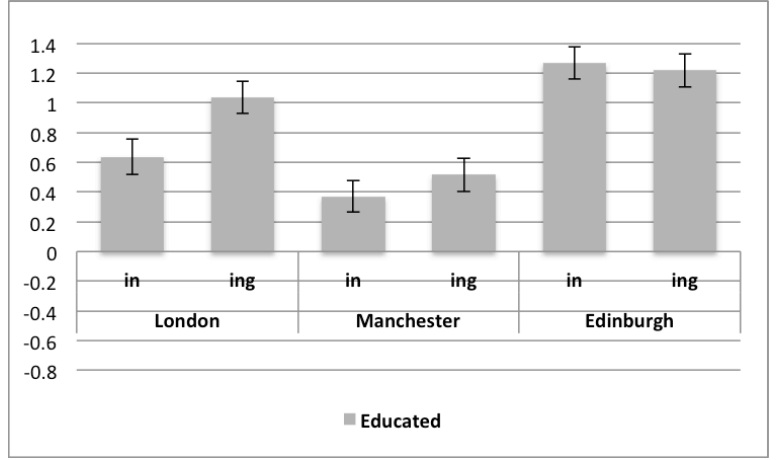

FIGURE 7. Means for educated.

\section{Additional social meanings in Edinburgh}

Finally, three additional scales, which do not appear to matter in any of the other two locales, emerge as significant in Edinburgh (see Table 5). [In]-stimuli were evaluated as significantly more down-to-earth, friendlier and trendier than [In]-stimuli. Since these are Edinburghspecific results and since scales relating directly to articulateness, poshness and wealth revealed no significant results, this may be an indication that the contrast between [II] and [In] is focused on somewhat different dimensions here. Edinburghers can use both [In] and [II] and be wealthy, and they can use both [In] and [II] and sound articulate; however, for many people, they cannot use [II] and sound down-to-earth, friendly and trendy.

Nevertheless, these main effects do not always apply: evaluation is very heterogeneous, as was the case elsewhere among Edinburgh participants. The [In]-guises only sound trendier to those who are less likely to use [In]: MC speakers. [In]-guises only sound friendlier to females and the down-to-earth effect applied only to two of the three voices. Thus, these effects are conditioned by who the hearers are and who the speaker is. 


\begin{tabular}{|c|c|c|c|}
\hline $\begin{array}{l}\text { Significant } \\
\text { scales }\end{array}$ & London & Manchester & Edinburgh \\
\hline $\begin{array}{l}\text { Down-to- } \\
\text { earth }\end{array}$ & - & - & $\begin{array}{l}\text { Variant: [In] > [II] } \\
\text { I: 1.04, E: 0.69, P: } 0.02 \\
\text { Variant* speaker } \\
\text { Elsa, Ed: [In] > [II] } \\
\text { Edie: [In] = [II] } \\
\text { I: } 1.04, \text { E: }-0.86, \text { P: } 0.04\end{array}$ \\
\hline Friendly & - & - & $\begin{array}{l}\text { Variant: [In] > [In] } \\
\text { I: } 1.21, \text { E: } 0.48, \text { P: }<.05 \\
\text { Variant*sex } \\
\text { Male: [Iy] > [In] } \\
\text { Female: [In] > [II] } \\
\text { I: } 1.21, \text { E: }-0.71, \text { P: } 0.03\end{array}$ \\
\hline Trendy & - & - & $\begin{array}{l}\text { Variant: }[\mathrm{In}]>[\mathrm{I}]] \\
\text { I: }-0.12, \text { E: } 0.63, \text { P: }<.01 \\
\text { Variant* social class } \\
\text { MC: }[\mathrm{In}]>[\mathrm{I}]] \\
\text { WC: }[\mathrm{In}]=[\mathrm{I}] \\
\text { I: }-0.12, \text { E: }-0.72, \text { P: } .03\end{array}$ \\
\hline
\end{tabular}




\section{DISCUSSION}

Attitudinal variation \& core social meanings?

We must, of course, exercise caution when interpreting null results and when trying to make generalisations. Nonetheless, we believe some tentative generalisations are certainly possible that speak to the three questions we posed, and we have dedicated the next three sections to discuss each in turn. The first key goal was to uncover what the social meanings of (ing) are in Britain, focusing on similarities, but also whether they differ in the locales investigated. The appropriate conclusion for our regional comparison seems to be that, between London, Manchester and Edinburgh, it is the Edinburgh data that often shows a different trend, whilst the Manchester results are roughly in line with the London results. There is also evidence for an evaluative shift as we move from London to Manchester and Edinburgh. However, this shift does not apply across the board. It is mediated by social characteristics of the population and by the historic spread of (ing), which led to differences in production.

As for similarities, there seems to be a small core of social meanings that many participants across Britain agree on, and this core appears to centre on formality as the only scale with significant results in all three locales. Social status is another possible contender for a core meaning of (ing), and we will explore below to what extent this is the case. These findings are in line with what we know about the transmission of linguistic variation. Labov (2001:437) remarks that "linguistic variation is transmitted to children as stylistic variation on the formal/informal dimension [...] Formal speech variants are associated by children with instruction and punishment, informal speech with intimacy and fun.” As linguistic development progresses, children learn that these informal speech variants are also associated with lower social status. Thus, it is no surprise to see the casual/formal scale emerge in all three locales, albeit interacting with social class in Manchester and Edinburgh. However, 
while the later association of informal variants with lower social status clearly happens in London and Manchester, there is little evidence for this in Edinburgh English.

It is important at this point to highlight the special Scottish situation. While Scotland is part of the UK, it does enjoy a certain degree of autonomy within it, and the idea of a Scottish nation is very strong within and outside of Scotland. Edinburgh English here refers to a continuum of Scottish English ranging from Scottish Standard English to traditional dialect, which is usually referred to as Scots. Scottish Standard English, a variety of Standard English spoken with a Scottish accent, is the result of a process of Anglicisation and erosion of Scots that has been ongoing since the sixteenth century (Aitken, 1979:92). In Scottish Standard English, (ing) is normally pronounced [II]. While Scots features are more likely to occur in the speech of working class individuals in Scotland as a whole, Chirrey (1999:224) argues that Edinburgh speakers tend towards standard varieties more so than other cities in Scotland. Most speakers in Edinburgh either speak Scottish Standard English or a variety somewhat in between Scottish Standard English and Scots.

The Scottish situation is interesting in regards to our discussion of an association of informal variants with lower social status because where such traces do emerge in Edinburgh, they are associated with education, intelligence and teaching: the domain where Scottish Standard English is most tangibly present for many Edinburghers. It is also the domain in which [II] entered the Edinburgh variety and was pushed forward most forcefully.

This is very much in contrast to the two English locations where we found direct, albeit weak, evidence that (ing) is associated with social class. This weak association of (ing) with social class is in line with Campbell-Kibler $(2009)^{10}$ and Levon and Fox (2014). Based on perception data, Levon and Fox (2014) argued recently that the primary association of variation in (ing) in Britain is not one of class. However, their study tests exclusively one 
scale; that of professionalism. Considering a wider range of evaluative dimensions results in a more complex picture.

Our study found an evaluative connection between [In] and a suspected WC background in London, but even here, it was more so the case for females than for males. Somewhat supportive evidence for the more complex relation between social class and (ing) comes from our findings for posh. The posh scale reaches statistical significance in London and Manchester, and the term posh certainly has class associations: it could be paraphrased as upper class, classy or stylishly luxurious. ${ }^{11}$ As we move north to Manchester and Edinburgh, there is less of a trace of this association (by finding interaction effects in Manchester, and no effects at all in Edinburgh).

This may be further evidence of the ideological link between social class and formality outlined by Labov (2001:437). As the connection between formality and (ing) becomes weaker in the North, that of social class also weakens. If our Edinburgh data is an indication of order in any way, formality associations are a prerequisite for social class associations, as clear class associations occur only in the two English locales, yet formality associations surface in all three. This suggests that, in communities where (ing) varies, the primary association of (ing) is one of formality. There may be a simple reason for this regional difference in associations. We outlined in our review that in the North, [In] is generally more frequently used by MC speakers than in the southern and internal areas. As a result, [In] may be used more in formal contexts in regions where it more frequently occurs in middle class speech. Consequences of the historical development of (ing), thus, are linked intimately with language use and, ultimately, language attitudes. 
We also asked how (historically-motivated) production patterns may relate to synchronous attitudinal patterns. Hypothetically, there may be at least three potential outcomes for attitudes towards (ing):

(1) all social groups agree on the evaluation of (ing)

(2) social groups may roughly agree on the social evaluation of (ing) but there may be some evidence of somewhat different evaluation of the variants in particular social groups: evaluative trends may be the same for these but this trend may be stronger in one social group than the other.

(3) social groups often differ in the social evaluation of (ing) to an extent that evaluative trends in one social group are occasionally the opposite of that in another social group.

Attitudes in Manchester and London are generally more homogeneous. We take this view based on fewer interaction effects in the data. Thus, for these two communities, an appropriate description for the type of attitudinal pattern appears to be (2). Where stratification occurs, it usually means that one social group considers both variants to have similar evaluations. In all these cases, there are significant main effects in addition to interaction effects. For Edinburgh, (3) seems the most apt description of attitude type. While social meanings of (ing) in the US, London and Manchester are relatively similar to each other, (ing) is subject to heterogeneous and apparent qualitatively different evaluation in Edinburgh.

This is an important finding because it tells us how attitudes to a specific variable may vary regionally as well as the degree of attitudinal variability we may encounter within a speech community. And we seem to have encountered two general evaluative patterns here: a relatively homogeneous social status/education/formality-based system with some moderate 
stratification in London and Manchester, and a stratified education, formality and social attractiveness-based one in Edinburgh. Thus, evaluative norms must be studied with care, particularly when they are used to define the speech community and when they are based on a feature that is used as heavily as [In] is in some social groups. Simultaneously, the stratified nature of evaluation regarding (ing) provides a partial answer to Labov's (1989:87) crucial question of how it is possible this variation was preserved for such a long time. Production as well as perception are separated socially, which allows for differential patterns in both to be maintained for a very long time. And this time has been much shorter in Scotland than in Southern England as the take-over of -ing for the participle did not start in Scotland until after the 16th century and even then the participle ending -and continued to have an identificational function in some literary Scots before it fell completely out of use in the 20th century (Görlach, 2002:96). ${ }^{12}$

Thus, [In] is not a vernacular, low prestige feature in the same way it is in London and Manchester, which is why, for many, [II] does not have associations with higher intelligence, better education, refinement, or increased degrees of dynamism. Whether this attitudinal difference applies generally beyond the line outlined by Houston (1985) is an empirical question. The fact that Scotland is its own political unit with a different tradition of writing and form of Standard English may additionally lead to the attitudinal outcome discussed above. An examination of the evaluation of (ing) in the far north of England, such as Tyneside (note the very low [Iy] values for Gateshead in Figure 1), would make an interesting test case as it would allow us to abstract away from the special political and linguistic status of English in Edinburgh, by comparing English in the Far North of England with English in Scotland. 
Question three asked whether listeners from different social backgrounds evaluate (ing) differently. And indeed, our study has found evidence that they do, but this finding brings up several theoretical issues regarding ideological variation and attitude type that must be addressed. Based on early sociolinguistic research (e.g., Labov, 1972:117), we would have expected type (1) to be the most common outcome when it comes to language attitudes. If attitudes are used to define what a community is, they would surely be quite similar. In fact, even in a type (2) community, attitudes are quite similar, but the findings we made for Edinburgh are somewhat unexpected. Below, we will try and provide a theoretical account for the heterogeneity observed in Edinburgh.

Ideology is the key here. It provides the framework used to make sense of variation in a speech community. Ideologies provide direction to indexical relations and the resulting social meanings. There are a variety of ways to define language ideologies. One that is particularly suited to our purposes is Irvine's (1989:255) definition of language ideologies as "the cultural system of ideas about social and linguistic relationships, together with their loading of moral and political interests." The advantage of this definition is that it allows language ideologies to be seen as multiple; in other words, there is language ideological variation that arises out of particular moral and political perspectives. A view of ideology that problematises language attitudinal and ideological variation (by social class, gender, etc.) is crucial; otherwise, it would promote an overly homogeneous view of language ideology within a community of speakers, such as that of London, or that of Manchester or Edinburgh. Kroskrity (2004:503) argues that it makes sense to view language ideologies as multiple and variable because there are a variety of social divisions in any locale. In fact, Eckert (2008:466-7) hypothesised that we should expect diversity in social meanings among subgroups of a community. In particular, Eckert assumed that class differences involve ideological differences about 
formality and displays of education and that working class and middle class individuals should have different attitudes. Indeed, we have found some such differences.

But, it strikes us that these are only part of the story. In Britain, ideological differences about formality and displays of education appear to be mediated by region. The case for different social classes having somewhat different attitudes with regards to these scales is much more convincing in Manchester than it is in London. Eckert's prediction proves correct in some locales more so than others, and we have provided arguments for why this may be the case. But in England, these are differences of degree, and they are in line with a view of standard language ideology (Lippi-Green, 2012:67) as multiple, without contradicting the existence of one standard language ideology.

For example, we know that the general population in London tends to consider [Iy]stimuli to be more educated than [In]-stimuli (Figure 7). This is replicated for working as well as middle class respondents, although at a slightly reduced scale among the working class respondents (Figure 8). And even though in Manchester this difference is so weak that it is insignificant, the principles by which variants are evaluated remain the same in subpopulations of the speech community. However, this is not the case in Edinburgh. These ideological principles only hold for MC speakers. For the majority of scales, there is no difference in the evaluation of (ing), or it is so weak that it does not rise above statistical significance. However, on some scales sub-populations within Edinburgh hold opinions that differ radically from each other. Many individuals regard [In] as perfectly suitable for formal, educated talk, and we have outlined some sociohistorical reasons to account for this. But how can these radically different evaluations be maintained and explained with reference to one standard language ideology in all of Edinburgh? 


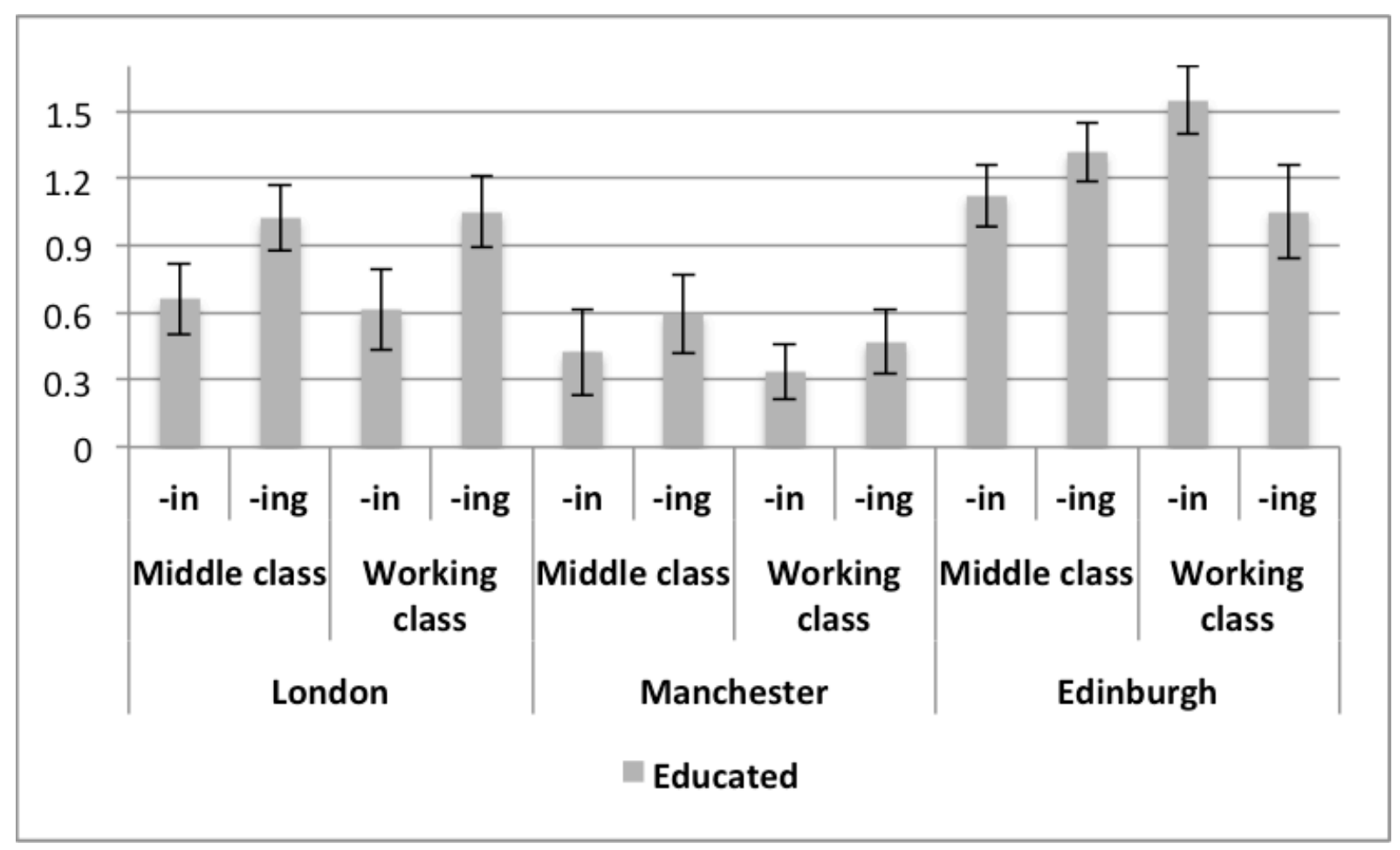

FIGURE 8. Mean evaluation of perceived educatedness of (ing)-guises.

We do not believe that the standard language ideology itself is of a fundamentally different nature in Scotland. When evaluating speakers, some, for example MC speakers, are clearly orienting towards Scottish Standard English, in which (ing) is normally pronounced [II]]. Other speakers are more likely to speak a variety closer to Scots, and Macaulay (1997:31) argues very strongly for nearby Glasgow speech that this is not wholly due to poverty and educational failure. This may provide the evaluative framework for many working class respondents in Edinburgh. We propose that the asymmetrical evaluation is due to participants' experience with variation in (ing) and that the asymmetry in use and evaluation does not necessarily contradict the existence of one standard language ideology within Edinburgh. It is normally assumed that the social meanings linguistic forms have for the speakers themselves arise out of indexical connections between the form and the contexts in which they are used 
(e.g., Kroskrity, 2004:500). This is key for the language situation in Edinburgh.

We can only deliberate about social meanings of (ing) for varieties that truly have the variants [Iy] and [In]. It is questionable whether this is the case for the conversational working class variety in Edinburgh. Romaine (1984:98) highlights that the use of [Iy] can be as low as zero among WC peers. Considering the stimuli were based on conversational Edinburgh speech, it would make sense for WC respondents to use norms of Edinburgh conversational speech in the evaluation of these stimuli. We do not mean to suggest that respondents do not have attitudes towards [II] but that they take variety (here Scottish English) and activity type into consideration when making their assessment. This would be in line with Walker et al.'s (2014) finding that respondents take into account the variety of the speaker when evaluating guises, and, we hypothesise, the speaker's activity type also.

Thus, this production-based expectation may influence the evaluation of (ing) variants. For MC speakers who may aim for a variety that is as close as possible to Scottish Standard English, [Iy] sounds perfectly reasonable, and is in line with acceptable stances of education and formality associated normally with standard speech. For WC speakers, [In] sounds odd and out of place. They rate [II] users down in regards to formality and education, either because they appear unauthentic or because these stances appear to them undesirable.

Such an explanation relies on a certain degree of variability at the ideological level. And, indeed, we have argued above that ideologies, too, can be variable. Thus, ideological variability can find expression in various ways, one being the association of a particular feature with degrees of articulateness, educatedness, etc. as we have observed among English participants and Scottish middle class participants yet it can also find expression in whether a particular feature - and in fact Scottish Standard English—is appropriate for a specific activity type at all; here: casual conversational speech. Thus, the issue is not whether standard language ideologies matter for sub-populations within Edinburgh — we believe they do; rather, 
the issue is whether standard features/speech should be used in certain activity types at all. Whether they are has evaluative repercussions: [II] use is penalised by some speakers. For many speakers, [In] should be used here, while [In] may create additional inferences; for example, regarding educatedness and intelligence. Further (experimental) evidence is required to test our hypotheses on the different context-appropriate norms regarding (ing), standard speech and differing evaluations of stances generated. What remains clear, though, is that the evaluative situation in Edinburgh is very distinct from that in the two English locales. It is also clear that attitudes and production are linked to a certain extent, as evaluations originate in participants' experience with variation in (ing).

\section{CONCLUSION}

In spite of the flexibility of social meanings associated with (ing), there is also clear semantic cohesion for the articulate $\sim$ inarticulate, hardworking lazy and formal $\sim$ casual scales between US results (Campbell-Kibler, 2009, 2011) and our results for London and Manchester and, to an extent, educated $\sim$ uneducated, intelligent $\sim$ thick and formal $\sim$ casual for the Edinburgh middle class. Considering that this comparison is limited to scales tested in all of these studies, ${ }^{13}$ the results suggest that (ing) has a similar indexical field of core meanings (Eckert, 2008) across US and British English varieties in which [I]] is used regularly in conversational speech.

Nonetheless, there is also a substantial degree of attitudinal variation between and within some communities. We have argued that awareness of language ideological variation and the historical development of (ing) within England and Scotland are crucial for a full understanding of the meaning of (ing) as we have provided evidence that shows how production and perception are separated socially, which allows for differential patterns in both to be maintained for a very long time. 


\section{NOTES}

1. For more detail, see Visser (1966:1095). These developments also appear to explain the grammatical conditioning of (ing) in many locales: "[T]he closer the construction is to a verbal construction, the greater the use of the apical variant, and the closer to a nominal construction, the greater the percentage of the velar variant" (Labov, 2001:79).

Tagliamonte (2004:399) found evidence in York, England, suggesting that grammatical categories also have a different set of constraints. Schleef, Meyerhoff and Clark (2011) found grammatical category not to matter at a significant level among London adolescents and only very weakly among Edinburgh adolescents.

2. We have also excluded other phonetic variants as our perception tests would not have been able to include all of them. For example, Wells (1982:262) discusses the potential occurrence of [n] and [ən] as a natural consequence of phonetic processes everywhere, particularly syllabic consonant formation. The variant [ən] can occur in English as well as Scottish English (e.g., Görlach, 2002:96), although we are not aware of a quantitative study that systematically differentiates [In] and [ən].

3. Such an experimental set-up is known as a between-subjects design. It is one of the most frequently used experiment types in the behavioural sciences alongside the within-subjects design. Several studies comparing both have resulted in some general guidelines as to when one should be favoured over the other (e.g., Charness, Gneezy, \& Kuhn, 2012; Greenwald, 1976; Keren \& Raaijmaker, 1988). Statistical and psychological factors (Greenwald, 1976: 314) and the particular problem that is to be answered (Keren \& Raaijmaker, 1988:233) must influence choice of approach. Within-subjects designs are particularly well-suited for the elicitation of direct subjective opinions and a series of other experimental types, but they create undesirable practice and demand effects, sensitisation and carry over (Greenwald, 1976:314) when the same speaker repeats the experiment. Our 
between-subjects design circumvents the problem of the listener recognising the speaker when hearing a stimulus twice with only slight modifications, while also reducing both survey time, boredom and practice effects. While this comes at the cost of the same speaker not hearing both stimuli pairs of an extract, any potential negative effects are outweighed by the much larger amounts of data one can, and has to, collect.

4. Word-final /t/ is occasionally glottalled or deleted by all nine speakers. There is no thfronting. The three Manchester speakers use the typical Northern $/ \mho /$ and $/ a /$ sounds in words such as but and bath respectively. One of the Manchester speakers (Mandy) drops the $/ \mathrm{h} /$ in the auxiliary have, and she is the only speaker in Manchester who uses one token of word-medial intervocalic glottalled / $t$ / in noticed. This is also true for one of the Edinburgh speakers (Edward) who glottalls /t/ in critical and written but not in criticising. The three Edinburgh speakers use typical Scottish vowels, for example, they apply the Scottish Vowel Length rule in words such as down and like.

5. Respondents were recruited in two ways: flyers and emails were sent to schools and universities for distribution to pupils and students; and the survey was advertised on a social network site. Once a respondent completed the survey, they were sent a thank you email asking them to pass the survey on to family and friends. Thus, participants were not limited to university students or a small number of social networks. Access to one of the local sub-surveys was randomised in order to balance the uptake.

6. Dörnyei (2003:104-5) discusses in detail these and similar cases under the heading of "data cleaning." Suspicious values that are inconsistent with the rest of the dataset should either be treated as outliers, or, if scrutiny of the data reveals that they are likely due to carelessness or dishonesty, they should be removed. Three pieces of evidence convinced us that we were dealing with the latter category of responses. First, all continuous responses just barely took longer than 5 minutes, which is an indication that these respondents did not 
engage with the task much. Second, there were few such responses, which suggests that these were not due to an attempt to negotiate the evaluation task in a meaningful regionspecific way, as the majority of respondents for any of the three areas did not select this strategy. Finally, we thought it extremely unlikely that any speaker would hear several different speakers, some of which used non-standard features in their guises and speak about different topics, and rate them all as equally educated, working-class, outgoing, etc. Continuous data points are, we felt, an implausible result in this specific questionnaire.

7. Data from matched guise studies are usually first subjected to a factor analysis, a technique that uncovers whether response patterns on a number of scales can be explained by a smaller number of underlying factors (Streiner, 1994:135). These scales could then be conflated to a smaller number of factors in any further statistical investigation, if certain criteria are met. While we conducted a series of factor analyses (excluding the binary personae of student and teacher for which such an analysis is not possible, Streiner, 1994:140) for the three regional data sets, as well as single speakers, we did not conflate any scales. The evaluative dimensions are highly similar in all three locales, each including prestige, solidarity, dynamism and formality factors. However, different scales are sometimes selected for these factors in the three locales. The basic principles of comparative sociolinguistics (Meyerhoff \& Schleef, 2013; Poplack \& Tagliamonte, 1991; Tagliamonte, 2002) dictate that elements to be compared (be they factors such as following phonological context, social class or, evaluative scales) are precisely the same. The goals of factor analysis are difficult to bring in line with those of comparative sociolinguistics, and we have decided to prioritise the latter.

8. A step-down method was used to construct the most efficient model. All factors and interactions were included initially in the baseline model, after which the non-significant 
factors were removed one-by-one. ANOVAs were used to test the improvement of successive models.

9. Note, however, the average values for posh in Figure 4. Results for this scale are insignificant in Edinburgh, due to heterogeneous evaluation.

10. Campbell-Kibler (2009:143-4) argued that the relationship between [In]-guises and uneducatedness/lack of intelligence is an indirect one: a significant effect only emerges if speakers are heard as working class. Working class on its own was not significant.

11. Posh, just like working class, may carry negative connotations for many people. Both are associated with certain personae and can easily be used to express a particular negative, neutral or positive stance. The point we would like to make here is that the association of (ing) with social class is stronger in the South than in the North of Britain and that the evaluation of posh is a reflection of this association.

12. Görlach (2002:96) explains that in Middle Scots participles remained distinct in the written language until the 16th century: - and and -yng were clearly distinguished. Even after that, in spoken Scots the two forms remained distinct for quite some time as -and forms were seldom used incorrectly for the verbal noun. They eventually fell together as [ən] or [In]. This pronunciation merger and the formal similarity of -yng and -ing, Görlach (2002:96) argues, resulted in the take-over of -ing for the participle.

13. Outgoing, down-to-earth, energetic, posh and rich were not included in CampbellKibler's $(2007,2009,2011)$ surveys. Similarly, we did not include bored, polite and gay in our study. 


\section{REFERENCES}

Aitken, Adam J. (1979). Scottish speech: A historical view with special reference to the Standard English of Scotland. In A. J. Aitken \& T. McArthur (eds.), The languages of Scotland. Edinburgh: Chambers. 85-119.

Boersma, Paul, \& Weenink, David. (2014). Praat: Doing phonetics by computer [computer program]. Version 5.3.82.

Campbell-Kibler, Kathryn. (2007). Accent, (ING) and the social logic of listener perceptions. American Speech 82:32-64.

Campbell-Kibler, Kathryn. (2009). The nature of sociolinguistic perception. Language Variation and Change 21:135-156.

Campbell-Kibler, Kathryn. (2011). The sociolinguistic variant as a carrier of social meaning. Language Variation and Change 22:423-441.

Charness, Gary, Gneezy, Uri, \& Kuhn, Michael A. (2012). Experimental methods: betweensubject and within-subject design. Journal of Economic Behavior \& Organization 81:1-8.

Chirrey, Deborah. (1999). Edinburgh: descriptive material. In P. Foulkes \& G.J. Docherty (eds.), Urban voices: Accent studies in the British Isles. London: Arnold. 223-229.

Dörnyei, Zoltán. (2003). Questionnaires in second language research: construction, administration and processing. Mahwah, NJ: Lawrence Erlbaum.

Eckert, Penelope. (2008). Variation and the indexical field. Journal of Sociolinguistics $12: 453-476$.

Eckert, Penelope. (2012). Three waves of variation study: the emergence of meaning in the study of sociolinguistic variation. Annual Review of Anthropology 41:87-100.

FluidSurveys. (2016). FluidSurveys: online survey software, URL http://fluidsurveys.com/. Ottawa, Canada [Last accessed: 29 March 2016].

Görlach, Manfred. (2002). A textual history of Scots. Heidelberg: C. Winter. 
Greenwald, Anthony G. (1976). Within-subjects designs: to use or not to use? Psychological Bulletin 83:314-320.

Hay, Jennifer, Drager, Katie, \& Warren, Paul. (2010). Short-term exposure to one dialect affects processing of another. Language and Speech 53:447-471.

Hazen, Kirk. (2006). IN/ING Variable. In Brown, K. (ed.), Encyclopaedia of language and linguistics. Oxford: Elsevier. 581-584.

Houston, Ann. (1985). Continuity and change in English morphology: the variable (ing). Doctoral dissertation, University of Pennsylvania.

Irvine, Judith T. (1989). When talk isn't cheap: language and political economy. American Ethnologist 16:248-267.

Jesperson, Otto. (1961). A Modern English grammar on historical perspectives. Part I: sounds and spellings. London: George Allen \& Unwin.

Johnstone, Barbara \& Kiesling, Scott. (2008). Indexicality and experience: exploring the meanings of /aw/-monophthongization in Pittsburgh. Journal of Sociolinguistics 12:5-33.

Keren, Gideon B., \& Raaijmakers, Jeroen G.W. (1988). On between-subjects versus withinsubjects comparisons in testing utility theory. Organizational Behavior and Human Decision Processes 41:233-247.

Kroskrity, Paul V. (2004). Language ideologies. In A. Duranti (ed.), A Companion to Linguistic Anthropology. Oxford: Blackwell. 496-517.

Labov, William. (1972). Sociolinguistic patterns. Philadelphia: University of Pennsylvania Press.

Labov, William. (1989). The child as a linguistic historian. Language Variation and Change $1: 85-97$.

Labov, William. (2001). Principles of linguistic change: social factors. Oxford: Blackwell. 
Labov, William, Ash, Sharon, Ravindranath, Maya, Weldon, Tracey, Baranowski, Maciej, \& Nagy, Naomi. (2011). Properties of the sociolinguistic monitor. Journal of Sociolinguistics 15:431-463.

Levon, Erez, \& Fox, Sue. (2014). Social salience and the sociolinguistic monitor: a case study of (ING) and TH-fronting in Britain. Journal of English Linguistics 42:185-217.

Lippi-Green, Rosina. (2012). English with an accent: language, ideology, and discrimination in the United States. Abingdon: Routledge.

Macaulay, Ronald K.S. (1997). Standards and variation in urban speech: examples from Lowland Scots. Amsterdam: John Benjamins.

Mathisen, Anne Grethe. (1999). Sandwell, West Midlands: ambiguous perspectives on gender patterns and models of change. In P. Foulkes \& G.J. Docherty (eds.), Urban voices: accent studies in the British Isles. London: Arnold. 107-123.

Mees, Inger. (1977). Language and social class in Cardiff: a survey of the speech habits of schoolchildren. MA dissertation, Leiden University.

Meyerhoff, Miriam, \& Schleef, Erik. (2013). Hitting an Edinburgh target: immigrant adolescents' acquisition of variation in Edinburgh English. In R. Lawson (ed.), Sociolinguistic perspectives on Scotland. Basingstoke: Palgrave Macmillan. 103-128.

Moore, Samuel, Meech, Sanford Brown, \& Whitehall, Harold. (1935). Middle English dialect characteristics and dialect boundaries. Ann Arbor: University of Michigan Press.

Pharao, Nicolai, Maegaard, Marie, Møller, Janus Spindler, \& Kristiansen, Tore. (2014). Indexical meanings of $\left[\mathrm{s}^{+}\right]$among Copenhagen youth: social perception of a phonetic variant in different prosodic contexts. Language in Society 43:1-31.

Poplack, Shana, \& Tagliamonte, Sali. (1991). African American English in the diaspora: the case of old-line Nova Scotians. Language Variation and Change 3:301-339. 
Preston, Dennis R. (2010). Variation in language regard. In P. Gilles, J. Scharloth, \& E. Ziegler (eds.), Empirische Evidenzen und theoretische Passungen sprachlicher Variation. Frankfurt am Main: Peter Lang. 7-27.

R Core Team. (2014). R: A language and environment for statistical computing, URL http://www.R-project.org/. Vienna, Austria: R Foundation for Statistical Computing.

Reid, Euan C. (1978). Social and stylistic variation in the speech of children: some evidence from Edinburgh. In P. Trudgill (ed.), Sociolinguistic patterns in British English. London: Arnold. 158-171.

Romaine, Suzanne. (1984). The language of children and adolescents. Oxford: Blackwell.

Schleef, Erik, \& Flynn, Nicholas E. J. (2015). Ageing meanings of (ing): age and indexicality in Manchester, England. English World-Wide 36:47-89.

Schleef, Erik, Flynn, Nicholas E.J, \& Ramsammy, Michael. (2015). Production and perception of (ing) in Manchester English. In E. Torgersen, S. Hårstad, B. Mæhlum, \& U. Røyneland (eds.), Language variation - European perspectives V. Amsterdam: John Benjamins.

Schleef, Erik, Meyerhoff, Miriam, \& Clark, Lynn. (2011). Teenagers' acquisition of variation: a comparison of locally-born and migrant teens' realisation of English (ing) in Edinburgh and London. English World-Wide 32:206-236.

Streiner, David L. (1994). Figuring out factors: the use and misuse of factor analysis. Canadian Journal of Psychiatry 39:135-140.

Tagliamonte, Sali. (2002). Comparative sociolinguistics. In J.K. Chambers, P. Trudgill, \& N. Schilling-Estes (eds.) The handbook of language variation and change. Oxford: Blackwell. 729-763.

Tagliamonte, Sali. (2004). Somethi[y]'s goi[n] on! Variable (ing) at ground zero. In B.-L. Gunnarsson, L. Bergstrom, G. Eklund, S. Fidell, L.H. Hansen, A. Karstadt, B. Nordberg, 
E. Sundergren, \& M. Thelander (eds.), Language variation in Europe. Uppsala: Uppsala University. 390-403.

Trudgill, Peter. (1974). The social differentiation of English in Norwich. Cambridge: Cambridge University Press.

Visser, Fredericus Th. (1966). An historical syntax of the English language. Part two: syntactical units with one verb. Leiden: E.J. Brill.

Walker, Abby, García, Christina, Cortés, Yomi, \& Campbell-Kibler, Kathryn. (2014). Comparing social meanings across listener and speaker groups: the indexical field of Spanish /s/. Language Variation and Change 26:169-189.

Watts, Emma. (2005). Mobility-induced dialect contact: a sociolinguistic investigation of speech variation in Wilmslow, Cheshire. Doctoral dissertation, University of Essex.

Wells, John C. (1982). Accents of English: an introduction. Cambridge. Cambridge University Press.

Zahn, Christopher J. \& Hopper, Robert. (1985). Measuring language attitudes: the speech evaluation instrument (SEI). Journal of Language and Social Psychology 4:113-123. 